\title{
Estimation of test-day model (co)variance components across breeds using New Zealand dairy cattle data
}

\author{
S. Vanderick, ${ }^{*}$ B. L. Harris, $†$ J. E. Pryce, $†$ and N. Gengler ${ }^{\star * 1}$ \\ *Animal Science Unit, Gembloux Agricultural University, B-5030 Gembloux, Belgium \\ †Livestock Improvement Corporation, Hamilton, New Zealand \\ $\ddagger$ National Fund for Scientific Research, B-1000 Brussels, Belgium
}

\section{ABSTRACT}

In New Zealand, a large proportion of cows are currently crossbreds, mostly Holstein-Friesians (HF) $\times$ Jersey (JE). The genetic evaluation system for milk yields is considering the same additive genetic effects for all breeds. The objective was to model different additive effects according to parental breeds to obtain first estimates of correlations among breed-specific effects and to study the usefulness of this type of random regression test-day model. Estimates of (co)variance components for purebred HF and JE cattle in purebred herds were computed by using a single-breed model. This analysis showed differences between the 2 breeds, with a greater variability in the $\mathrm{HF}$ breed. (Co)variance components for purebred $\mathrm{HF}$ and JE and crossbred HF $\times$ JE cattle were then estimated by using a complete multibreed model in which computations of complete across-breed (co)variances were simplified by correlating only eigenvectors for $\mathrm{HF}$ and JE random regressions of the same order as obtained from the single-breed analysis. Parameter estimates differed more strongly than expected between the single-breed and multibreed analyses, especially for JE. This could be due to differences between animals and management in purebred and nonpurebred herds. In addition, the model used only partially accounted for heterosis. The multibreed analysis showed additive genetic differences between the HF and JE breeds, expressed as genetic correlations of additive effects in both breeds, especially in linear and quadratic Legendre polynomials (respectively, 0.807 and 0.604$)$. The differences were small for overall milk production (0.926). Results showed that permanent environmental lactation curves were highly correlated across breeds; however, intraherd lactation curves were also affected by the breed-environment interaction. This result may indicate the existence of breed-specific competition effects that vary through the

Received October 19, 2007.

Accepted August 29, 2008.

${ }^{1}$ Corresponding author: gengler.n@fsagx.ac.be different lactation stages. In conclusion, a multibreed model similar to the one presented could optimally use the environmental and genetic parameters and provide breed-dependent additive breeding values. This model could also be a useful tool to evaluate crossbred dairy cattle populations like those in New Zealand. However, a routine evaluation would still require the development of an improved methodology. It would also be computationally very challenging because of the simultaneous presence of a large number of breeds.

Key words: crossbreeding, Holstein-Friesian, Jersey, multibreed model

\section{INTRODUCTION}

Crossbreeding is a method used for improving animal production in pigs, beef cattle, and poultry (e.g., Wei and van der Werf, 1995). However, it has not been widely used in dairy cattle in most temperate countries until recently because of the high milk production of the Holstein-Friesian (HF) breed (Touchberry, 1992). Most current purebred HF populations in the world were created by upgrading existing European Friesian or similar populations. Harris and Kolver (2001) gave a more detailed history of the New Zealand HF (NZHF) population that showed the different phases. The original NZHF population was first developed from animals imported from the West Coast of the United States before 1925, and it then remained as a closed population. Most of the cattle before 1960 (approximately 75\%) were Jersey (JE). Therefore, until the early 1980s upgrading was first from JE to NZHF by using locally available sires. The descendants of this process remained lighter than overseas HF (OSHF) from North America or Europe. Since the 1980s, OSHF sires have become more popular. However, the daughters of these animals are heavier and seem to be less fertile and have decreased survival rates (Harris and Kolver, 2001). Therefore, most New Zealand dairy farmers have not upgraded to OSHF, and as a result of this experience, there has been even more widespread popularity of crossbreeding. Even though dairy farmers in North America and 
Europe were very reluctant to crossbreed at that time, crossbreeding has been a feature of the history of the dairy industry of New Zealand. Currently, more than one-third of dairy replacements are crossbred, mostly $\mathrm{HF} \times \mathrm{JE}$. This is because both breeds, the HF and JE, are economically comparable under typical New Zealand production systems (e.g., Lopez-Villalobos and Garrick, 2002), and complementarity characteristics from these breeds and heterosis effects favor crossbreds (e.g., Lopez-Villalobos and Garrick, 2002). Crossbreeding provides a good opportunity to maximize the net income per hectare under New Zealand pastoral conditions by improving fertility and survival, and also by improving (or altering) the composition of milk, which is very important because the dairy company payment structures reward farmers for the amount of milk solids (fat and protein) produced. Therefore, crossbreds benefit from the high volumes achieved in the HF breed as well as from the beneficial fat and protein composition of the JE breed (Montgomerie, 2002). Several studies have demonstrated the economic superiority of crossbred $\mathrm{HF} \times \mathrm{JE}$ cows in New Zealand (e.g., LopezVillalobos and Garrick, 1996, 1997; Lopez-Villalobos et al., 2002) and potentially elsewhere (e.g., VanRaden and Sanders, 2001).

Additionally, crossbred bulls are currently being progeny tested by the major New Zealand breeding companies in response to farmer requests. Farmers are willing to accept a reduction in heterosis to have a type of cow that they recognize as being the most profitable for their system, even when heterosis effects are ignored.

From 1996 to the beginning of 2007, New Zealand dairy cattle were genetically evaluated across breeds for yield traits by using a 2-step test-day model, in which test-day production records were combined to predict 270-d yields, and an animal model was used for the genetic evaluation of these predicted yields (Harris, 1994, 1995). A new test-day model has been developed to use the milk production herd-test data to calculate breeding values, and this new system has been implemented since February 2007 (Harris et al., 2006). The evaluated production traits are then included in an economic index called breeding worth, which describes animal profitability per unit of feed (this is a feature of the across-breed evaluation; Johnson, 1996; Garrick et al., 1997). Heterosis is modeled as a fixed effect in the model, correcting for mean differences. Thus, genetic contributions from purebreds to crossbreds are only partly taken into account; therefore, it does not allow an optimal use of crossbred data. Moreover, a study by Wei and van der Werf (1995) showed that an optimal use of crossbred information jointly with purebred information in selection could bring more genetic progress in crossbreds. To do this, genetic correlation of additive effects in different breeds has to be known. Such results are rare, if not nonexistent, in dairy cattle, whereas in swine or in beef cattle, such results are less unusual (e.g., Lutaaya et al., 2001; Newman et al., 2002; Roso et al., 2005; Zumbach et al., 2007).

The objective of this study was to model different additive effects according to breed composition to estimate correlations among breed-specific effects. The second objective was also to study the usefulness of this type of a more complicated random regression test-day model.

\section{MATERIALS AND METHODS}

\section{Data}

Data were provided by the Livestock Improvement Corporation, Hamilton, New Zealand, and comprised records on cows from dedicated progeny-testing herds. The original data comprised 223,141 animals in production and a total of 500,134 animals in the pedigree.

Only animals of HF and JE inheritance were kept to estimate (co)variance components; therefore, animals whose summed proportion of $\mathrm{HF}$ and JE genes was less than $100 \%$ were eliminated. No distinction was made among HF animals with different compositions of OSHF and NZHF genes; they were considered to belong to the same breed. This was also done to limit the study to a 2-breed situation. Data were limited to first-lactation test-day milk yields, which were recorded for 208,164 cows in 3,481 herds with test days, equally spaced across the lactation at 2-mo intervals. After these edits, the breed composition of animals with records in first lactation was approximately $54 \%$ $\mathrm{HF}, 21 \% \mathrm{JE}$, and $25 \% \mathrm{HF} \times \mathrm{JE}$, and the distribution of herds per breed composition showed that $65 \%$ of herds had $\mathrm{HF} \times \mathrm{JE}, \mathrm{HF}$, and JE or were entirely composed of $\mathrm{HF} \times \mathrm{JE}$ animals; $25 \%$ of herds were purebred $\mathrm{HF}$ and only $10 \%$ were purebred JE. In the context of this article, purebred means at least $95 \%$ of $\mathrm{HF}$ or JE genes. Crossbreds consequently were animals with a major breed composition of between 50\% (included) and $95 \%$ (excluded) HF or JE genes.

Data sets were constructed based on a stratification of herds as a function of their average breed proportions. Herds with average breed compositions of $95 \%$ and more HF or JE genes were considered purebred herds. Similarly, herds with an average breed composition of between $50 \%$ (included) and $95 \%$ (excluded) HF or JE genes were considered crossbred herds. Within the purebred herds, only animals whose proportions of $\mathrm{HF}$ or JE genes were $95 \%$ or more were selected. Because the data set was still too large for analysis, ad- 
Table 1. Composition, daily milk yield average, and standard deviations of purebred and crossbred samples ${ }^{1}$ used in this study

\begin{tabular}{|c|c|c|c|c|c|c|}
\hline \multirow[b]{2}{*}{ Sample } & \multirow[b]{2}{*}{ Herds, n } & \multirow[b]{2}{*}{$\begin{array}{c}\text { Cows in } \\
\text { production, } \mathrm{n}\end{array}$} & \multicolumn{2}{|c|}{ Test-day records } & \multicolumn{2}{|c|}{ Daily milk yield, kg } \\
\hline & & & $\mathrm{n}$ & $\begin{array}{l}\text { Average per } \\
\text { lactation, } \mathrm{n}\end{array}$ & Average & $\mathrm{SD}$ \\
\hline HF 1 & 160 & 11,721 & 44,531 & 3.8 & 13.30 & 4.35 \\
\hline HF 2 & 166 & 11,952 & 45,326 & 3.8 & 13.08 & 4.38 \\
\hline HF 3 & 165 & 11,748 & 45,324 & 3.9 & 13.68 & 4.46 \\
\hline JE 1 & 107 & 7,703 & 29,512 & 3.8 & 9.94 & 3.14 \\
\hline JE 2 & 105 & 7,671 & 30,605 & 4.0 & 9.76 & 3.03 \\
\hline $\mathrm{HF} \times \mathrm{JE} 1$ & 64 & 4,966 & 19,048 & 3.8 & 12.78 & 4.22 \\
\hline $\mathrm{HF} \times \mathrm{JE} 2$ & 48 & 4,918 & 19,769 & 4.0 & 12.50 & 4.20 \\
\hline $\mathrm{HF} \times \mathrm{JE} 3$ & 44 & 4,990 & 19,486 & 3.9 & 12.85 & 4.33 \\
\hline $\mathrm{HF} \times \mathrm{JE} 4$ & 60 & 4,959 & 18,305 & 3.7 & 12.62 & 4.21 \\
\hline $\mathrm{HF} \times \mathrm{JE} 5$ & 64 & 4,968 & 18,017 & 3.6 & 12.11 & 4.20 \\
\hline
\end{tabular}

ditional samplings were made on a herd base, in which animals within herds were kept together and randomly assigned to data sets. For purebred herds, $3 \mathrm{HF}$ and 2 JE data sets were created. For crossbred herds, 5 data sets were created, composed of purebred and crossbred animals. Table 1 lists the number of herds, animals in production, test-day records, and records per lactation for the purebred and crossbred data sets used in this study. Means and standard deviations of daily milk yields are also given.

\section{Models}

The research was conducted in 2 steps. First, estimation of (co)variance components for purebred HF and JE cattle was done by using a simple single-breed model. Hereafter, this study is called a single-breed analysis. (Co)variance components for purebred $\mathrm{HF}$ and $\mathrm{JE}$ and crossbred HF $\times$ JE cattle were then estimated by using a complete multibreed model. This study was considered to be an across-breed analysis, hereafter called a multibreed analysis. The reasons for using this strategy were 2 -fold. First, we wanted to simplify actual estimations by estimating within and then across breeds. Second, this strategy allowed us to compare the results from both analyses. We acknowledge that there were 2 types of herds (purebred vs. crossbred), implying that differences should be expected.

Single-Breed Analysis. (Co)variance components were estimated for HF and JE breeds separately by using the purebred data sets. The single-breed model used was a random regression test-day model, written as

$$
\mathbf{y}=\mathbf{X b}+\mathbf{Q}_{\mathbf{h}} \mathbf{h}+\mathbf{Q}_{\mathbf{a}} \mathbf{a}+\mathbf{Q}_{\mathbf{p}} \mathbf{p}+\mathbf{e},
$$

where $\mathbf{y}$ is a vector of first-lactation test-day yields; $\mathbf{b}$ is a vector of fixed effects for herd $\times$ test-day date, lactation stage (defined as classes of 5 DIM), gestation stage (definition based on $24 \mathrm{~d}$ carried calf classes), and regressions on age at calving within lactation periods (defined as 4 classes based on DIM: 5 to 64,65 to 119 , 120 to 184 , and greater than 184) $\times$ calving season (March to June, July, August, September to December) × calving period (before 1994, 1994 to 1998, and after 1998) classes; and $\mathbf{h}, \mathbf{a}$, and $\mathbf{p}$ are vectors of unknown herd $\times$ calving year, permanent environmental, and additive genetic random regression effects; $\mathbf{Q}_{\mathbf{h}}, \mathbf{Q}_{\mathbf{a}}$, and $\mathbf{Q}_{\mathbf{p}}$ are the covariate matrices for the third-order Legendre polynomials; linking $\mathbf{h}$, $\mathbf{a}$, and $\mathbf{p}$ with $\mathbf{y}$ and $\mathbf{e}$ is a vector of unknown residuals. The (co)variance matrices associated with the 3 random effects were $\operatorname{Var}(\mathbf{h})=\mathbf{I}_{h} \otimes \mathbf{H}, \operatorname{Var}(\mathbf{p})=\mathbf{I}_{p} \otimes \mathbf{P}$, and $\operatorname{Var}(\mathbf{a})=\mathbf{A}_{a} \otimes \mathbf{G}$, where $\mathbf{H}, \mathbf{P}$, and $\mathbf{G}$ were the elementary (co)variance matrices across the 3 Legendre polynomials. A random herd $\times$ calving year period effect was included to model potential additional environmental covariances because of a common herd and time-dependent effect. This random effect was defined as a combination between herds and 7 periods of 2 yr of calving from 1989 to 2002. Hereafter, this effect is called the herd period. The (co)variances among residuals were modeled as $\operatorname{Var}(\mathbf{e})=\mathbf{I}_{n} \sigma_{e}^{2}$, where $\sigma_{e}^{2}$ was the residual variance and $\mathbf{I}_{n}$ was an identity matrix of dimension $\mathrm{n}$, where $\mathrm{n}$ is the number of records. By keeping this variance constant, we modeled differences in environmental variance across DIM by the other environmental random effects.

Multibreed Analysis. The model used for the multibreed analysis was similar to those used for the single- 
breed studies, with 2 differences. In the definition of fixed effects, regressions on age at calving were computed within breed $\times$ lactation period $\times$ calving season $\times$ calving period classes, where breed was defined as previously: purebred HF, purebred JE, or crossbred $\mathrm{HF} \times \mathrm{JE}$. Effects of heterosis and recombination should be partially taken into account by this effect. All other fixed effects were defined without considering the breed of animals. The second difference was in the definition of random effects. Based on the results from the withinbreed analysis and to simplify the estimation of (co) variance components across breeds, initial Legendre polynomials were transformed into 3 new independent regressions contained in the covariate matrices $\mathbf{Q}_{\mathrm{Th}}$, $\mathbf{Q}_{\mathbf{T a}}$, and $\mathbf{Q}_{\mathbf{T p}}$ by using diagonalizations based on the following decompositions: $\mathbf{H}=\mathbf{T}_{h} \mathbf{D}_{h} \mathbf{T}_{h}{ }^{\prime}, \mathbf{P}=\mathbf{T}_{p} \mathbf{D}_{p} \mathbf{T}_{p}{ }^{\prime}$, and $\mathbf{G}=\mathbf{T}_{a} \mathbf{D}_{a} \mathbf{T}_{a}$ '. Original covariance structures were transformed to become $\operatorname{Var}\left(\mathbf{h}_{\mathbf{T}}\right)=\mathbf{I}_{h} \otimes \mathbf{D}_{h}$, $\operatorname{Var}\left(\mathbf{p}_{\mathbf{T}}\right)=\mathbf{I}_{p} \otimes \mathbf{D}_{p}$, and $\operatorname{Var}\left(\mathbf{a}_{\mathbf{T}}\right)=\mathbf{A}_{a} \otimes \mathbf{D}_{a}$ based on $\operatorname{Var}(\mathbf{h})=\mathbf{I}_{h} \otimes \mathbf{T}_{h} \mathbf{D}_{h} \mathbf{T}_{h}{ }^{\prime}, \quad \operatorname{Var}(\mathbf{p})=\mathbf{I}_{p} \otimes \mathbf{T}_{p} \mathbf{D}_{p} \mathbf{T}_{p}{ }^{\prime}, \quad$ and $\operatorname{Var}(\mathbf{a})=\mathbf{A}_{a} \otimes \mathbf{T}_{a} \mathbf{D}_{a} \mathbf{T}_{a}{ }^{\prime}$. To achieve equivalence between the original and the transformed model, transformed regression matrices required to model a record $\mathrm{i}$ were defined as $\quad \mathbf{Q}_{\mathbf{T h}(i)}=\mathbf{Q}_{\mathbf{h}(i)} \mathbf{T}_{\mathbf{h}}, \quad \mathbf{Q}_{\mathbf{T a}(i)}=\mathbf{Q}_{\mathbf{a}(i)} \mathbf{T}_{\mathbf{a}}, \quad$ and $\mathbf{Q}_{\mathbf{T}(i)}=\mathbf{Q}_{\mathbf{p}(i)} \mathbf{T}_{\mathbf{p}}$. Equivalence can be shown by rewriting the original model [1] for a single observation i:

$$
y_{(i)}=\mathbf{X}_{(i)} \mathbf{b}_{(i)}+\mathbf{Q}_{\mathbf{h}(i)} \mathbf{h}_{(i)}+\mathbf{Q}_{\mathbf{a}} \mathbf{a}_{(i)}+\mathbf{Q}_{\mathbf{p}} \mathbf{p}_{(i)}+e_{(i)} .
$$

The transformed model becomes

$$
\begin{gathered}
y_{(i)}=\mathbf{X}_{(i)} \mathbf{b}_{(i)}+\mathbf{Q}_{\mathbf{T h}(i)} \mathbf{h}_{\mathbf{T}(i)} \\
+\mathbf{Q}_{\mathbf{T a}(i)} \mathbf{a}_{\mathbf{T}(i)}+\mathbf{Q}_{\mathbf{T} \mathbf{p}(i)} \mathbf{p}_{\mathbf{T}(i)}+e_{(i)},
\end{gathered}
$$

where, based on the equivalence between models [2] and [3], the following formulas can be established:

$$
\begin{gathered}
\operatorname{Var}\left(\mathbf{Q}_{\mathbf{T h}(i)} \mathbf{h}_{\mathbf{T}(i)}\right)=\mathbf{Q}_{\mathbf{T h}(i)} \operatorname{Var}\left(\mathbf{h}_{\mathbf{T}(i)}\right) \mathbf{Q}_{\mathbf{T h}(i)}{ }^{\prime} \\
=\mathbf{Q}_{\mathbf{T h}(i)} \mathbf{D}_{h} \mathbf{Q}_{\mathbf{T h}(i)}{ }^{\prime}=\mathbf{Q}_{\mathbf{h}(i)} \mathbf{T}_{\mathbf{h}} \mathbf{D}_{h} \mathbf{T}_{\mathbf{h}}{ }^{\prime} \mathbf{Q}_{\mathbf{h}(i)}{ }^{\prime} \\
=\mathbf{Q}_{\mathbf{h}(i)} \mathbf{H Q}_{\mathbf{h}(i)}{ }^{\prime}, \\
\operatorname{Var}\left(\mathbf{Q}_{\mathbf{T a}(i)} \mathbf{a}_{\mathbf{T}(i)}\right)=\mathbf{Q}_{\mathbf{T a}(i)} \operatorname{Var}\left(\mathbf{a}_{\mathbf{T}(i)}\right) \mathbf{Q}_{\mathbf{T a}(i)}{ }^{\prime} \\
=\mathbf{Q}_{\mathbf{T a}(i)} \mathbf{D}_{\mathbf{a}} \mathbf{Q}_{\mathbf{T a}(i)}{ }^{\prime}=\mathbf{Q}_{\mathbf{a}(i)} \mathbf{T}_{a} \mathbf{D}_{a} \mathbf{T}_{a} \mathbf{Q}_{\mathbf{a}(i)}{ }^{\prime} \text { and } \\
=\mathbf{Q}_{\mathbf{a}(i)} \mathbf{G Q}_{\mathbf{a}(i)}{ }^{\prime},
\end{gathered}
$$

$$
\begin{gathered}
\operatorname{Var}\left(\mathbf{Q}_{\mathbf{T} \mathbf{p}(i)} \mathbf{p}_{\mathbf{T}(i)}\right)=\mathbf{Q}_{\mathbf{T} \mathbf{p}(i)} \operatorname{Var}\left(\mathbf{p}_{\mathbf{T}(i)}\right) \mathbf{Q}_{\mathbf{T} \mathbf{p}(i)}{ }^{\prime} \\
=\mathbf{Q}_{\mathbf{T} \mathbf{p}(i)} \mathbf{D}_{p} \mathbf{Q}_{\mathbf{T} \mathbf{p}(i)}{ }^{\prime}=\mathbf{Q}_{\mathbf{p}(i)} \mathbf{T}_{a} \mathbf{D}_{a} \mathbf{T}_{a}{ }^{\prime} \mathbf{Q}_{\mathbf{p}(i)}{ }^{\prime} \\
=\mathbf{Q}_{\mathbf{p}(i)} \mathbf{P Q}_{\mathbf{p}(i)}{ }^{\prime} .
\end{gathered}
$$

By using the transformation, the global single-breed model could therefore be rewritten as

$$
\mathbf{y}=\mathbf{X b}+\mathbf{Q}_{\mathbf{T h}} \mathbf{h}_{\mathbf{T}}+\mathbf{Q}_{\mathbf{T a}} \mathbf{a}_{\mathbf{T}}+\mathbf{Q}_{\mathbf{T p}} \mathbf{p}_{\mathbf{T}}+\mathbf{e}
$$

Based on model [2], an appropriate multibreed model considering separate random effects per breed would be written as

$$
\begin{aligned}
\mathbf{y} & =\mathbf{X} \mathbf{b}+\Phi^{(H F)}\left(\mathbf{Q}_{\mathbf{h}} \mathbf{h}^{(H F)}+\mathbf{Q}_{\mathbf{a}} \mathbf{a}^{(H F)}+\mathbf{Q}_{\mathbf{p}} \mathbf{p}^{(H F)}\right) \\
& +\Phi^{(J E)}\left(\mathbf{Q}_{\mathbf{h}} \mathbf{h}^{(J E)}+\mathbf{Q}_{\mathbf{a}} \mathbf{a}^{(J E)}+\mathbf{Q}_{\mathbf{p}} \mathbf{p}^{(J E)}\right)+\mathbf{e},
\end{aligned}
$$

where $\Phi^{(H F)}$ and $\Phi^{(J E)}$ are diagonal incidence matrices containing the fraction of breed compositions linking observations to random effects. Notation of fractions of the breed composition of animals is written as $\varphi_{(i)}^{(H F)}$ and $\varphi_{(i)}^{(J E)}$ for every record i, with values being obviously identical for all records of the same animal. The feature of this model was that the definition of the covariate matrices included a multiplication with the fraction of HF, respectively, JE breed contributions. To simplify computations and based on model [3], the following transformed model was used:

$$
\begin{aligned}
\mathbf{y} & =\mathbf{X b}+\mathbf{Q}_{\mathbf{T h}}^{(H F)} \mathbf{h}_{\mathbf{T}}^{(H F)}+\mathbf{Q}_{\mathbf{a}}^{(H F)} \mathbf{a}_{\mathbf{T}}^{(H F)}+\mathbf{Q}_{\mathbf{p}}^{(H F)} \mathbf{p}_{\mathbf{T}}^{(H F)} \\
& +\mathbf{Q}_{\mathbf{T h}}^{(J E)} \mathbf{h}_{\mathbf{T}}^{(J E)}+\mathbf{Q}_{\mathbf{a}}^{(J E)} \mathbf{a}_{\mathbf{T}}^{(J E)}+\mathbf{Q}_{\mathbf{p}}^{(J E)} \mathbf{p}_{\mathbf{T}}^{(J E)}+\mathbf{e}
\end{aligned}
$$

where breed-specific regressions for a given record i are $\mathbf{Q}_{\mathbf{T h}(i)}^{(H F)}=\varphi_{(i)}^{(H F)} \mathbf{Q}_{\mathbf{T h}(i)}, \quad \mathbf{Q}_{\mathbf{T a}(i)}^{(H F)}=\varphi_{(i)}^{(H F)} \mathbf{Q}_{\mathbf{T a}(i)}, \quad$ and $\mathbf{Q}_{\mathbf{T} \mathbf{p}(i)}^{(H F)}=\varphi_{(i)}^{(H F)} \mathbf{Q}_{\mathbf{T} \mathbf{p}(i)} \quad$ for $\mathrm{HF}$ and $\quad \mathbf{Q}_{\mathbf{T h}(i)}^{(J E)}=\varphi_{(i)}^{(J E)} \mathbf{Q}_{\mathbf{T h}(i)}$, $\mathbf{Q}_{\mathbf{T a}(i)}^{(J E)}=\varphi_{(i)}^{(J E)} \mathbf{Q}_{\mathbf{T a}(i)}$, and $\mathbf{Q}_{\mathbf{T} \mathbf{p}(i)}^{(J E)}=\varphi_{(i)}^{(J E)} \mathbf{Q}_{\mathbf{T} \mathbf{p}(i)}$ for JE.

Computations of complete across-breed (co)variances were simplified by correlating only eigenvectors for $\mathrm{HF}$ and JE of the same order. The associated (co)variance matrices among these transformed random effects could then be shown grouped by type of effects:

$$
\operatorname{Var}\left(\begin{array}{l}
\mathbf{h}_{\mathbf{T}}^{(H F)} \\
\mathbf{h}_{\mathbf{T}}^{(J E)}
\end{array}\right)=\mathbf{I}_{h} \otimes\left(\begin{array}{cc}
\mathbf{D}_{h}^{(H F)} & \mathbf{D}_{h}^{(H F \times J E)} \\
\mathbf{D}_{h}^{(H F \times J E)} & \mathbf{D}_{h}^{(J E)}
\end{array}\right),
$$




$$
\begin{gathered}
\operatorname{Var}\left(\begin{array}{l}
\mathbf{p}_{\mathbf{T}}^{(H F)} \\
\mathbf{p}_{\mathbf{T}}^{(J E)}
\end{array}\right)=\mathbf{I}_{p} \otimes\left(\begin{array}{cc}
\mathbf{D}_{p}^{(H F)} & \mathbf{D}_{p}^{(H F \times J E)} \\
\mathbf{D}_{p}^{(H F \times J E)} & \mathbf{D}_{p}^{(J E)}
\end{array}\right) \text {, and } \\
\operatorname{Var}\left(\begin{array}{l}
\mathbf{a}_{\mathbf{T}}^{(H F)} \\
\mathbf{a}_{\mathbf{T}}^{(J E)}
\end{array}\right)=\mathbf{A}_{a} \otimes\left(\begin{array}{cc}
\mathbf{D}_{a}^{(H F)} & \mathbf{D}_{a}^{(H F \times J E)} \\
\mathbf{D}_{a}^{(H F \times J E)} & \mathbf{D}_{a}^{(J E)}
\end{array}\right) .
\end{gathered}
$$

The diagonal matrices $\mathbf{D}^{(H F \times J E)}$ for every type of random effect contained the (co)variances across breeds among transformed regressions. Transformations were done in a way that forced the order of eigenvectors for $\mathrm{HF}$ and JE to remain identical (largest to smallest). This procedure is not a rank reduction, but makes the computations more robust because it concentrates (co) variances among breeds into 3 values instead of 6 . Initial tests showed that stable convergence of variance component estimation procedures required the use of this procedure. In addition, interpretation of the (co) variances among breeds was simplified. The basic assumption was that the eigenvectors stayed similar if we compared the single-breed and multibreed models.

Heterogeneity of residual variances was expected for animals with different breed compositions. Therefore, breed composition was used to calculate weights to standardize residual variances and to adjust for the expected heterogeneous residual variances. The weight for a record $i$ of a given animal was defined as

$$
\text { weight }_{(i)}=\left[\frac{H F_{p} \times \sqrt{\left(\sigma_{e}^{2}\right)^{(H F)}}+J E_{p} \times \sqrt{\left(\sigma_{e}^{2}\right)^{(J E)}}}{\varphi_{(i)}^{(H F)} \times \sqrt{\left(\sigma_{e}^{2}\right)^{(H F)}}+\varphi_{(i)}^{(J E)} \times \sqrt{\left(\sigma_{e}^{2}\right)^{(J E)}}}\right]^{2},
$$

where $H F_{p}$ and $J E_{p}$ are the average breed proportion for breed HF and JE of the population used for the estimations; $\left(\sigma_{e}^{2}\right)^{(H F)}$ and $\left(\sigma_{e}^{2}\right)^{(J E)}$ are the residual variances estimated with the single-breed model; and $\varphi_{(i)}^{(H F)}$ and $\varphi_{(i)}^{(J E)}$ are the breed proportions for breed HF and JE of a record $i$ of a given animal in production. The (co) variances among unknown residuals were modeled as $\operatorname{Var}(\mathbf{e})=\mathbf{W} \sigma_{e}^{2}$, where $\sigma_{e}^{2}$ was the multibreed residual variance, and the matrix diagonal matrix $\mathbf{W}$ contained the inverse of the weight for every record.

\section{Estimation of (Co)variance Components}

(Co)variance components were estimated by using REML. The expectation-maximization algorithm
(EM) with acceleration EM-REML was used. This algorithm estimates the parameters by indirect approximation of the first derivative of the likelihood function. Expectation-maximization-REML is very stable but the convergence rate is very slow (Misztal, 2002). Therefore, the average information REML algorithm (Jensen et al., 1997) was also used. It uses approximate second derivatives and is computationally more demanding, although it requires fewer iterations to converge. However, convergence problems appeared when the (co)variance matrices were not positive definite (Meyer, 1997; Misztal et al., 2000), and most of the computations needed to be done by EM-REML, which proved to be more stable.

\section{RESULTS AND DISCUSSION}

\section{Single-Breed Analysis}

The (co)variance components were estimated for each sample, and from these estimates, the means and standard deviations of the samples for each breed were calculated. Results for variances and (co)variances for constant, linear, and quadratic random regression coefficients are presented in Table 2. In general, estimates were quite consistent across the $3 \mathrm{HF}$ and 2 JE samples, except for the herd-period effect in HF, which showed a greater variability.

Variances of random effects, except for the residual variances, which were considered to be constant, varied with DIM because of the use of random regression models. Phenotypic variances for milk as a function of DIM for HF and JE breeds are shown in Figure 1. The HF breed showed a greater variability than the JE breed, as confirmed by the herd-period, permanent environment, and genetic variance patterns of the 2 breeds (Figure 2). This can be explained mainly by a scale effect caused by the greater production of HF. It is also likely that HF showed greater genetic variability because of the importation of HF genetic material from overseas (Canada, United States, or Europe), especially since the $1980 \mathrm{~s}$, creating 2 different HF strains (a NZHF strain and an imported OSHF strain). Harris and Kolver (2001) have reviewed the effect of Holsteinization on pastoral dairy farming and have discussed the differences between the $2 \mathrm{HF}$ strains in New Zealand. In this study, we did not distinguish between the 2 strains because the genetic difference between the $2 \mathrm{HF}$ strains can be considered less important than the one between $\mathrm{HF}$ and JE. Animals of nonnative JE origin are also present in New Zealand pedigrees, although to a much lesser degree.

Herd-period variance trends are given in Figure 2. The trajectory of this variance was less pronounced in 
Table 2. Mean and standard deviation of variances and (co)variance (liters ${ }^{2}$ ) for constant, linear, and quadratic random regression coefficients from single-breed models

\begin{tabular}{|c|c|c|c|c|c|c|c|c|c|c|c|c|}
\hline \multirow{2}{*}{ Item } & \multicolumn{6}{|c|}{$\mathrm{HF}^{1}$ purebreds } & \multicolumn{6}{|c|}{$\mathrm{JE}^{2}$ purebreds } \\
\hline & \multicolumn{2}{|c|}{ Constant } & \multicolumn{2}{|c|}{ Linear } & \multicolumn{2}{|c|}{ Quadratic } & \multicolumn{2}{|c|}{ Constant } & \multicolumn{2}{|c|}{ Linear } & \multicolumn{2}{|c|}{ Quadratic } \\
\hline \multicolumn{13}{|l|}{ Residual } \\
\hline Constant & 17.771 & 1.211 & & & & & 8.674 & 0.537 & & & & \\
\hline \multicolumn{13}{|l|}{ Herd period } \\
\hline Quadratic & -0.366 & 0.880 & -0.500 & 0.376 & 0.415 & 0.365 & 1.503 & 0.403 & -0.920 & 0.201 & 0.457 & 0.274 \\
\hline \multicolumn{13}{|c|}{ Permanent environment } \\
\hline Constant & 17.538 & 1.072 & & & & & 8.434 & 0.760 & & & & \\
\hline Linear & -7.943 & 0.338 & 4.172 & 0.641 & & & -3.701 & 0.112 & 2.055 & 0.170 & & \\
\hline Quadratic & 1.674 & 0.257 & -1.971 & 0.400 & 3.268 & 0.097 & 0.601 & 0.227 & -0.972 & 0.115 & 1.610 & 0.204 \\
\hline \multicolumn{13}{|l|}{ Genetic } \\
\hline Constant & 12.355 & 0.839 & & & & & 7.455 & 0.713 & & & & \\
\hline
\end{tabular}

${ }^{1} \mathrm{HF}=$ Holstein-Friesian

${ }^{2} \mathrm{JE}=$ Jersey.

HF but was generally greater than for JE. The differences may be due to a difference in management between the HF and JE purebred herds in New Zealand. For example, the greater stocking rates of the JE breed could be an explanation for these differences in variability. Another assumption is that the geographical location of HF and JE herds could have influenced the results. Bryant et al. (2007a) showed that HF and $\mathrm{JE}$ have reacted differently to differences in climate or altitude. Incidentally, purebred JE herds are more common in the northern part of the North Island, whereas purebred HF herds are more common in the cooler parts of the South Island.

Lactation variances were computed over a standard $270-d$ lactation. Table 3 presents the variances and relative values obtained when compared with phenotypic variance. The values confirmed the previous results in Figure 2, showing greater relative herd period variances and slightly greater relative genetic variances for JE. Residual variance on a lactation basis was very low because environmental correlations across DIM were taken into account by other environmental effects, but residual correlations among DIM were assumed to be zero.

Daily estimates of genetic and phenotypic correlations between different stages of lactation and daily estimates of heritabilities are presented in Table 4, with heritabilities on the diagonal, genetic correlations above the diagonal, and phenotypic correlations below the diagonal. As expected, these correlations became weaker as the interval between tests increased. On average, correlations were greater for JE than HF animals. Heritability estimates increased from the beginning un- til the end of the lactation for both breeds. This trend was confirmed by the representation of heritabilities for milk yield as a function of DIM, as illustrated in Figure 3. According to Figure 3, purebred HF animals had a greater heritability than JE animals at the beginning of lactation, but from 60 DIM, the trend was reversed. As reported in Table 2, the heritability for 270-d lactation yields (represented by the genetic relative variance) were similar for HF and JE purebreds (respectively, 0.31 and 0.32 ), and these values were slightly less than the heritability estimate used for the genetic evaluation of milk in New Zealand (0.36; Interbull, 2007). These estimates were not totally in line with the literature (e.g., Ahlborn and Dempfle, 1992; Interbull, 2007), in which values of heritabilities for the lactation milk yield trait for the JE breed tended to be greater than those for HF. For example, in the United States, heritabilities of 0.25 to 0.35 are used for the Holstein breed and 0.30 to 0.40 are used for the JE breed (Interbull, 2007). However, there may be other reasons to explain our results.

\section{Multibreed Analysis}

As for the single-breed analysis, (co)variance components estimated for each sample were averaged. Means and standard deviations of variances and (co)variances for constant, linear, and quadratic random regression coefficients are given in Table 5. The patterns and magnitude of heritability estimates were different between the single-breed and multibreed analyses, especially for JE purebred animals on a daily basis (see Figure 3 ). Values of variances and heritability estimates computed for a 


\section{A) Single-breed model}

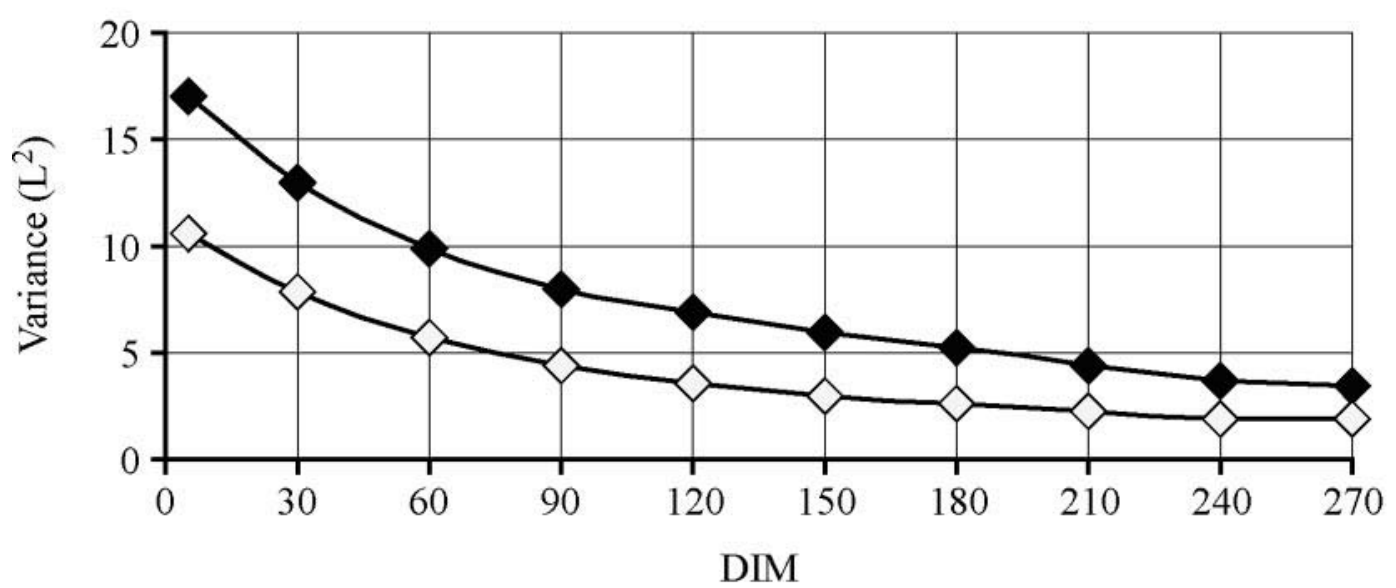

B) Multibreed model $\begin{array}{ll}\square \mathbf{1 0 0} \% \text { Holstein-Friesian } \\ \square \mathbf{7 5} \% \text { Holstein-Friesian, 25\% Jersey } \\ \square \mathbf{5 0} \% \text { Holstein-Friesian, } \mathbf{5 0} \% \text { Jersey Hersey }\end{array}$

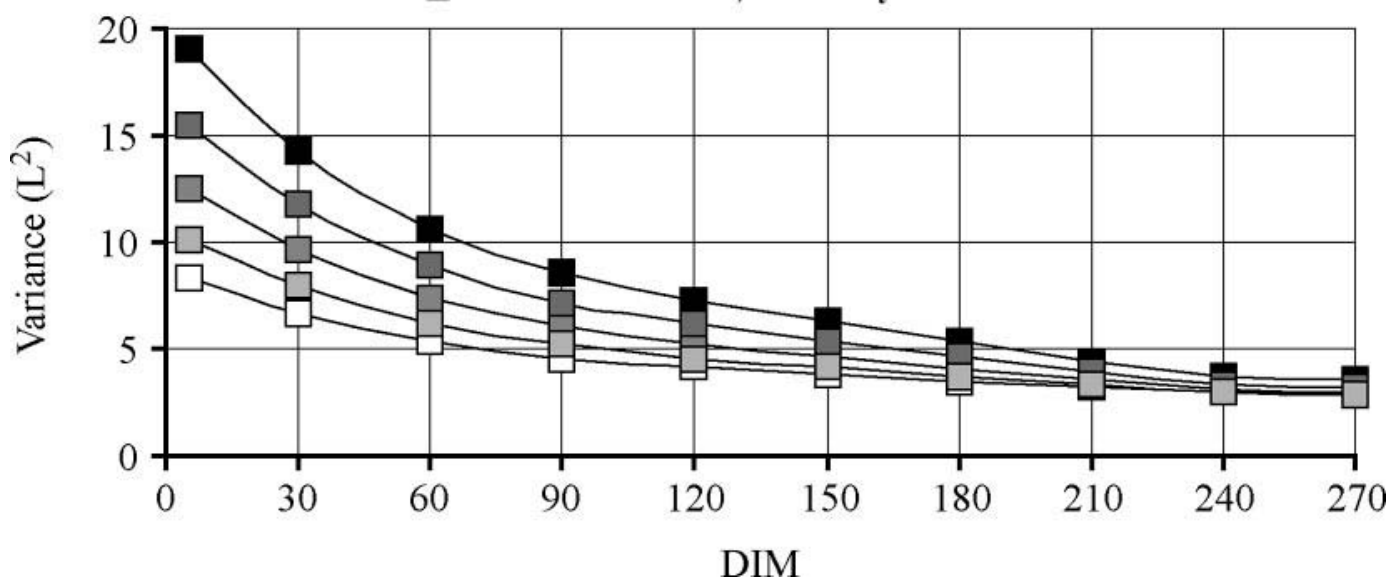

Figure 1. A) Comparison of phenotypic variances obtained by the single-breed analysis for Holstein-Friesian $(\bullet)$ and Jersey $(\diamond)$ animals for milk as function of DIM. B) Comparison of phenotypic variances obtained by the multibreed analysis for purebred and crossbred animals.

270-d lactation are presented in Table 6. These results were also quite different (mainly for JE animals) from those obtained in the single-breed models. They were more in line with the literature, albeit slightly lower (e.g., Ahlborn and Dempfle, 1992; Interbull, 2007). As confirmed by the values in Tables 3 and 6 , the lacta- tion heritability for JE changed from 0.32 to 0.52 when changing from the single-breed to the multibreed model. Figure 2 shows that a greater genetic variance and a lower herd-period estimate from the multibreed analysis for JE animals induced the difference in heritability. Interpretation of these large differences is not easy. A first

Table 3. Variances $\left(\right.$ liters $\left.^{2} \times 10,000\right)$ and relative variances to phenotypic computed for a lactation of 270 DIM in the single-breed models of purebred Holstein-Friesian (HF) and Jersey (JE) animals

\begin{tabular}{lccccc}
\hline & \multicolumn{2}{c}{ HF purebreds } & & \multicolumn{2}{c}{ JE purebreds } \\
\cline { 2 - 3 } \cline { 5 - 6 } Type of variance & Variance & Relative & & Variance & Relative \\
\hline Phenotypic & 31.8 & 1.00 & & 18.4 & 1.00 \\
Permanent environment & 14.5 & 0.46 & & 7.00 & 0.38 \\
Genetic & 9.91 & 0.31 & & 5.87 & 0.32 \\
Herd period & 7.31 & 0.23 & & 5.55 & 0.30 \\
Residual & 0.05 & 0.00 & & 0.02 & 0.00 \\
\hline
\end{tabular}


potential reason could be the difference in the types of animals in each study because completely different data sets were used. In addition, the management between purebred herds and herds considered crossbred could partially explain these differences. This hypothesis is supported by the change in the JE herd-period variance with a decrease in the estimated value from 5.55 (single breed) to 1.45 (multibreed). The JE herd-period vari- ance was, in fact, as much as 4 times greater, mainly for the first half of the lactation, in the single-breed model than in the multibreed model. Few differences in permanent environmental variances were observed between the single-breed model and the multibreed model (see Figure 2). Finally, the multibreed model used did not fully account for heterosis. This could also have inflated observed genetic variance. This hypothesis was

\section{A) Herd-period}

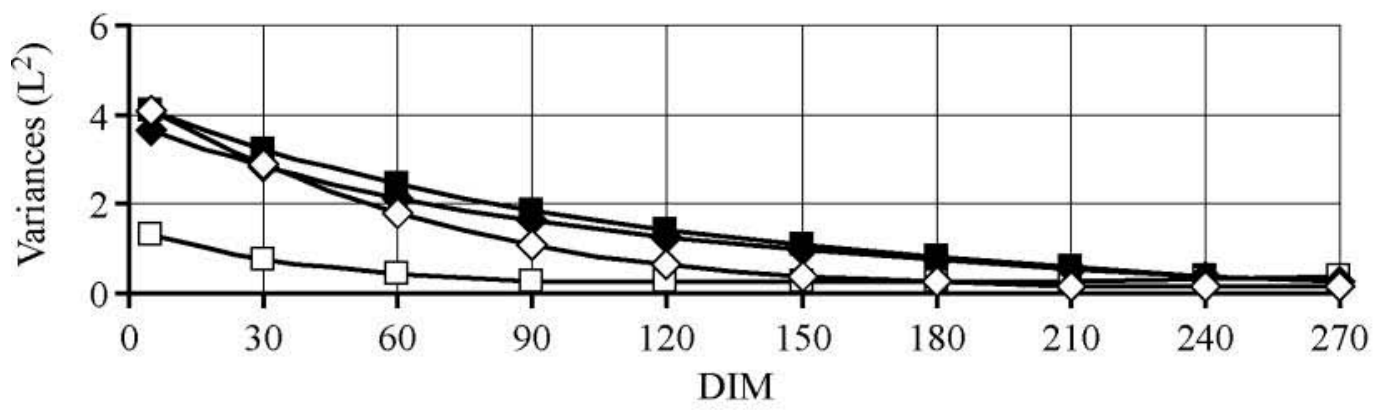

B) Permanent environment

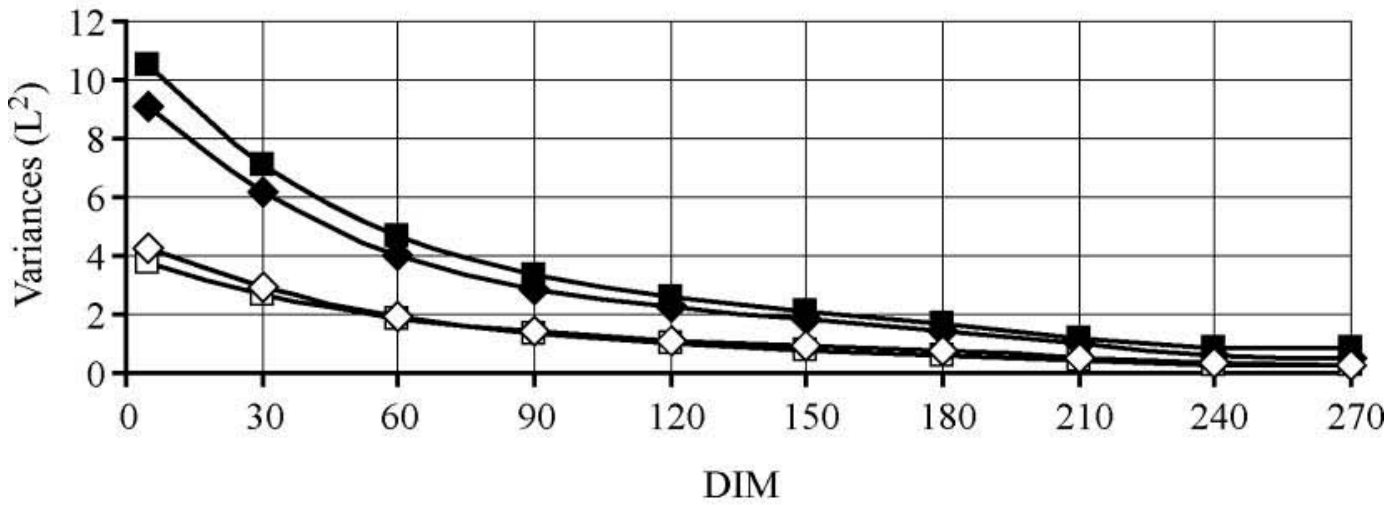

C) Additive genetic

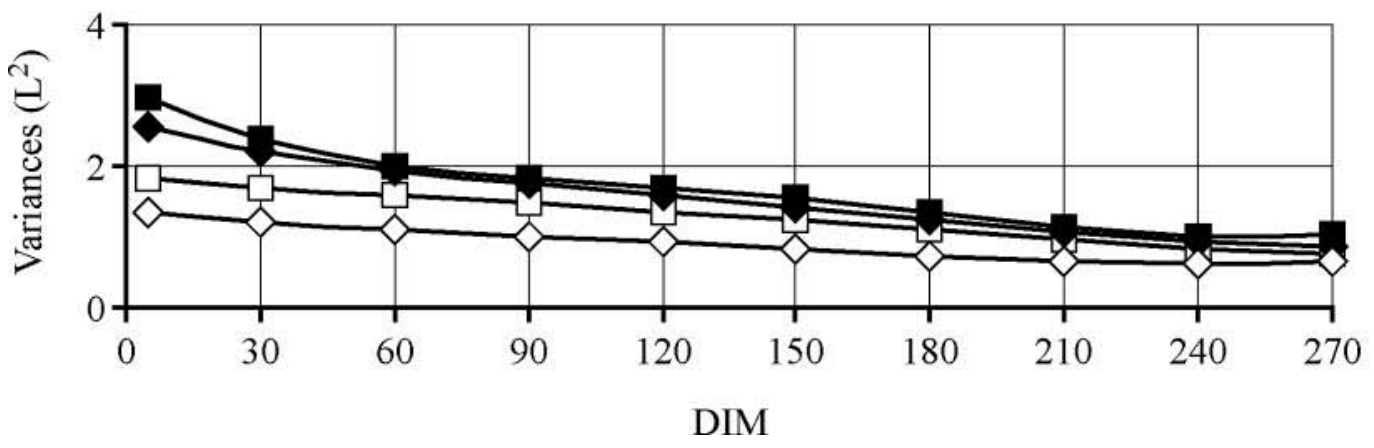

Figure 2. Herd-period (A), permanent environment (B), and additive genetic variances (C) for milk as function of DIM estimated by using the single-breed $(\diamond, \bullet)$ and multibreed models $(\square, \boldsymbol{\square})$ for Holstein-Friesian (solid symbols) and Jersey (open symbols) animals. 
Table 4. Heritabilities, and genetic (above diagonal) and phenotypic (below diagonal) correlations for daily milk yields among first lactation, estimations from single-breed models for Holstein-Friesian and Jersey animals

\begin{tabular}{lccccc}
\hline & \multicolumn{5}{c}{ DIM } \\
\cline { 2 - 5 } Item & 5 & 60 & 120 & 180 & 270 \\
\hline Holstein-Friesian & & & & & \\
5 & 0.150 & 0.954 & 0.844 & 0.739 & 0.575 \\
60 & 0.804 & 0.197 & 0.965 & 0.896 & 0.670 \\
120 & 0.597 & 0.719 & 0.231 & 0.977 & 0.747 \\
180 & 0.415 & 0.581 & 0.672 & 0.241 & 0.841 \\
270 & 0.361 & 0.401 & 0.408 & 0.458 & 0.255 \\
Jersey & & & & & \\
5 & 0.126 & 0.960 & 0.880 & 0.816 & 0.622 \\
60 & 0.840 & 0.192 & 0.976 & 0.925 & 0.630 \\
120 & 0.648 & 0.746 & 0.259 & 0.978 & 0.665 \\
180 & 0.471 & 0.608 & 0.684 & 0.285 & 0.782 \\
270 & 0.466 & 0.479 & 0.457 & 0.447 & 0.350 \\
\hline
\end{tabular}

A)

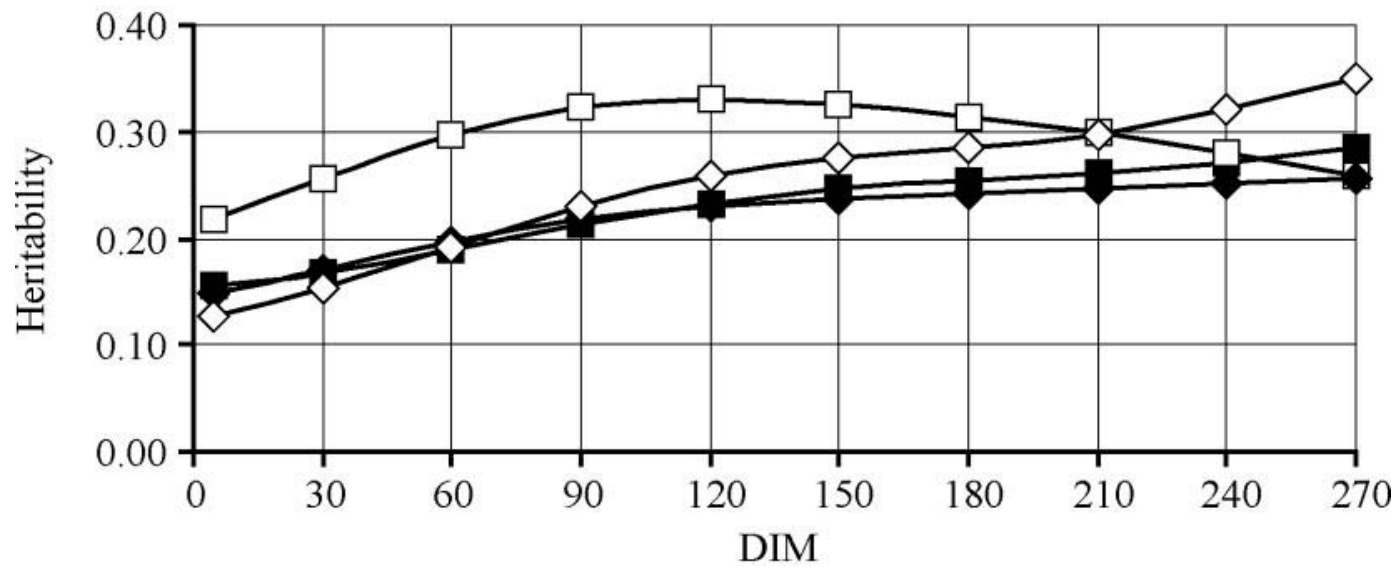

B)

$100 \%$ Holstein-Friesian

$\square \mathbf{2 5} \%$ Holstein-Friesian, $75 \%$ Jersey

$\square \mathbf{7 5} \%$ Holstein-Friesian, 25\% Jersey $\square \mathbf{1 0 0} \%$ Jersey

$\square \mathbf{5 0} \%$ Holstein-Friesian, $\mathbf{5 0} \%$ Jersey

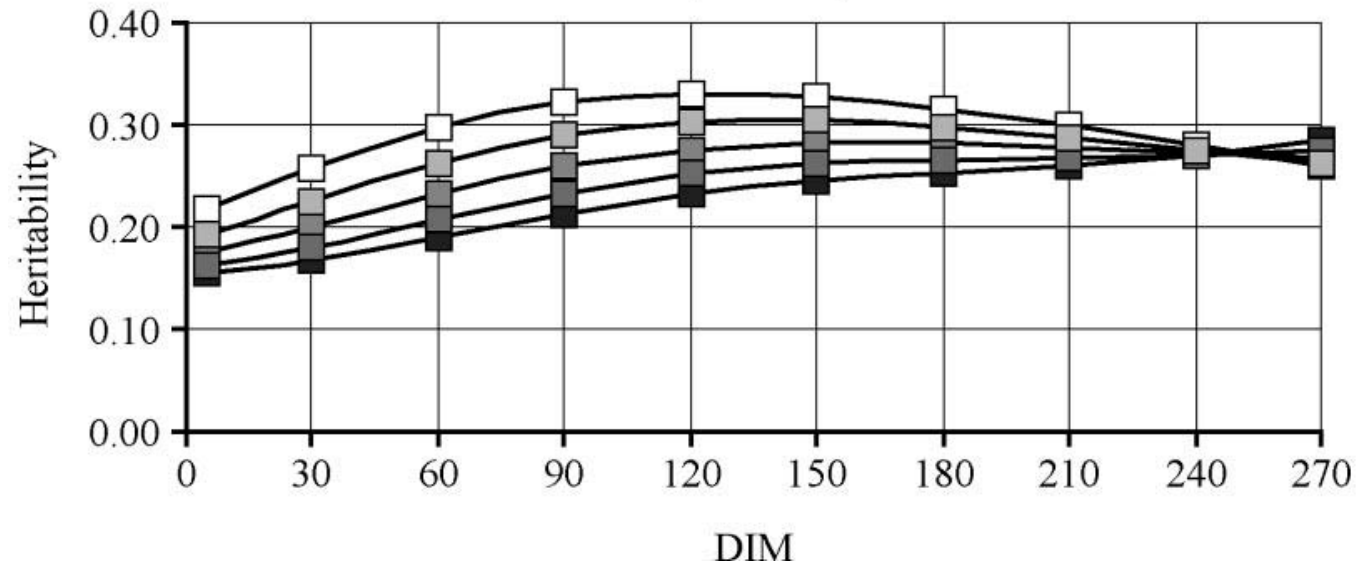

Figure 3. Heritabilities for milk as a function of DIM estimated by using single-breed $(\diamond, \bullet)$ and multibreed models ( $\square$, $\mathbf{\square})$ for purebred Holstein-Friesian (solid symbols) and Jersey (open symbols) animals (A) and for purebred and crossbred animals using the multibreed model (B). 
Table 5. Mean and standard deviation of variances and (co)variance (liters ${ }^{2}$ ) for constant linear and quadratic random regression coefficients from the multibreed model

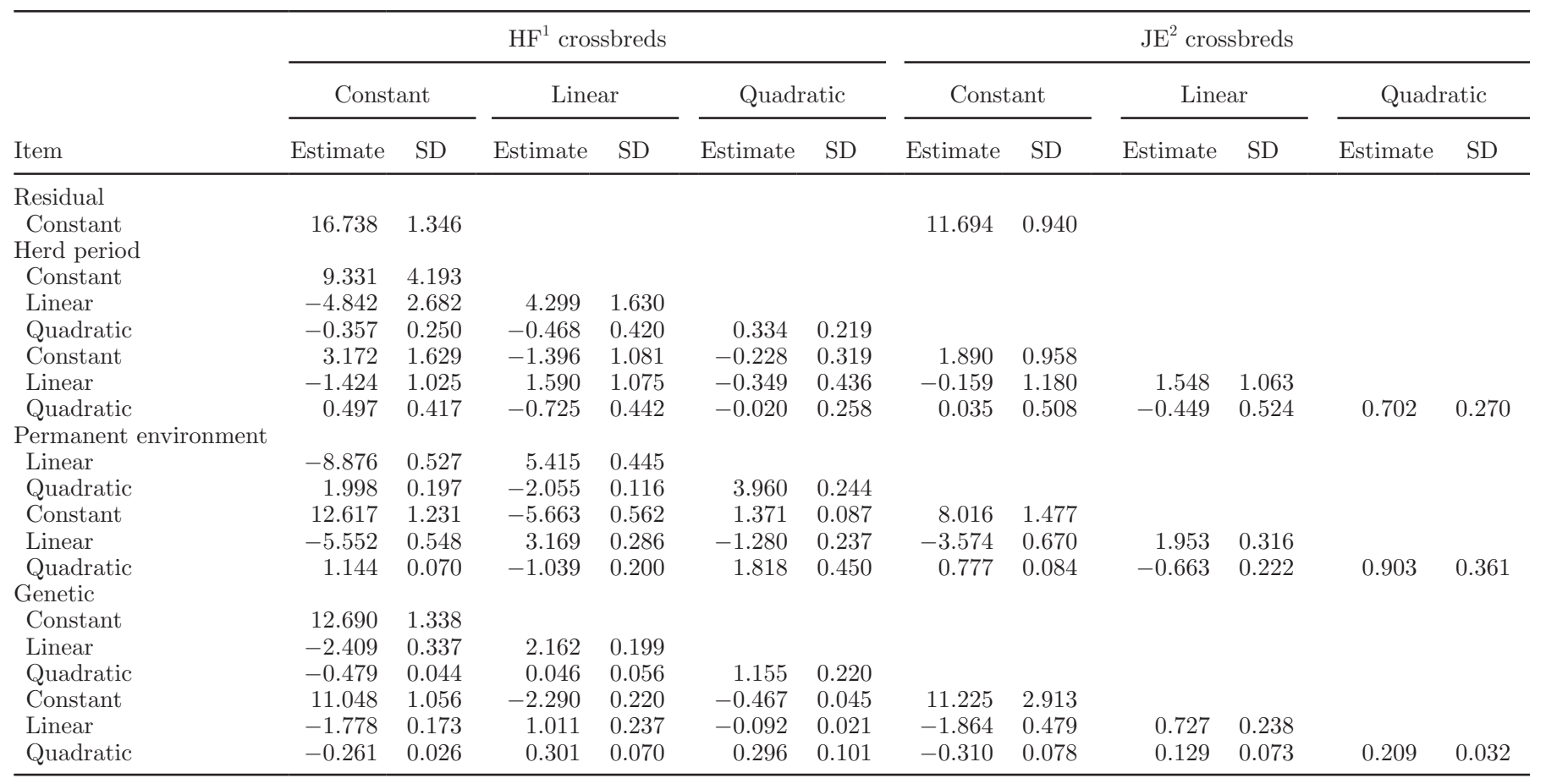

${ }^{1} \mathrm{HF}=$ Holstein-Friesian.

${ }^{2} \mathrm{JE}=$ Jersey.

supported by the observed increase in genetic variance for JE when comparing the single-breed and multibreed models, where 5.87 became 8.85 .

Only JE showed the large increase in heritability. Previous research by Lofgren et al. (1985) also showed a greater sensitivity of this breed, compared with HF, to changes in herd environments, expressed as means and standard deviations of contemporary groups adjusted for genetic differences. As shown in Table 1, means and standard deviations for daily milk yields were approximately $30 \%$ greater in the multibreed data sets compared with the purebred JE data sets. Lofgren et al. (1985) reported that similar differences in means and standard deviations, but in a purebred setting, generated a substantial increase in heritability (as much as 50\%). Earlier studies (e.g., Legates, 1962, for fat yields) showed similar results, again in JE. It is very difficult to explain these results, but they are in line with ours. It seems possible to imagine that, in particular, greater average yields in JE are linked to larger animals, which could better express genetic differences. Because crossbred JE should be larger, this hypothesis could remain valid in our study.

From the (co)variances estimated with the multibreed model, variances for milk as a function of DIM were computed for $\mathrm{HF} \times \mathrm{JE}$ crossbred animals. Results are

Table 6. Variances and relative variances computed for a lactation of 270 DIM from the multibreed model for purebred and crossbred animals

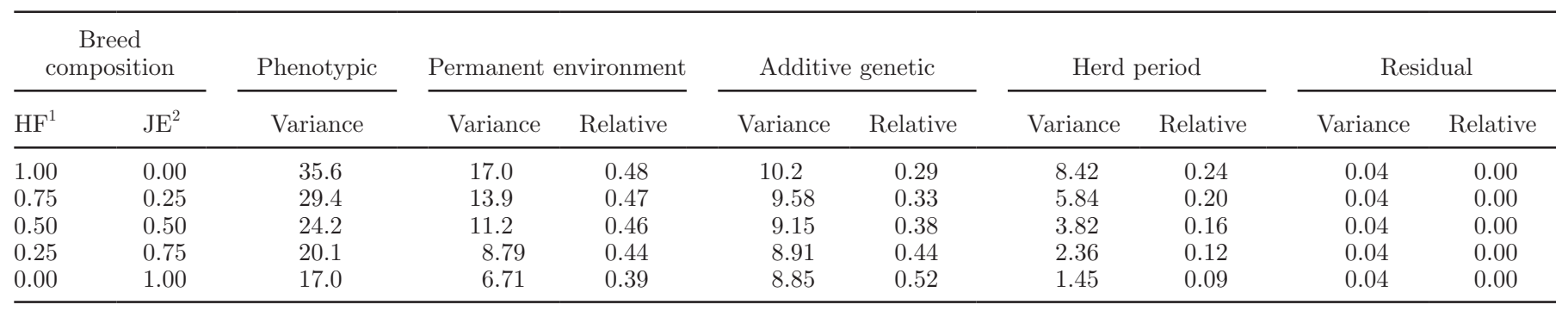

${ }^{1} \mathrm{HF}=$ Holstein-Friesian

${ }^{2} \mathrm{JE}=$ Jersey 
Table 7. Correlations among Legendre polynomial regressions across Holstein-Friesian and Jersey breeds estimated from the multibreed model (values shown were obtained by back-transformation)

\begin{tabular}{lccc}
\hline & \multicolumn{3}{c}{ Effect } \\
\cline { 2 - 4 } Polynomial & $\begin{array}{c}\text { Herd } \\
\text { period }\end{array}$ & $\begin{array}{c}\text { Permanent } \\
\text { environment }\end{array}$ & $\begin{array}{c}\text { Additive } \\
\text { genetic }\end{array}$ \\
\hline Constant & 0.755 & 0.989 & 0.926 \\
Linear & 0.616 & 0.974 & 0.807 \\
Quadratic & -0.040 & 0.961 & 0.604 \\
\hline
\end{tabular}

given for first-cross animals of the 2 purebreds $(\mathrm{HF}=$ $50 \%$ and $\mathrm{JE}=50 \%)$ and back-crosses between $\mathrm{F}_{1}$ and purebreds ( $\mathrm{HF}=75$ or $25 \%$ and $\mathrm{JE}=25$ or $75 \%$ ). Only phenotypic variances (Figure 1) as a function of DIM are presented, showing the evolution over the lactation. The variances for $\mathrm{HF} \times \mathrm{JE}$ crossbred animals were between those of the purebreds and followed the same trend as in purebred animals. These were confirmed by the values of variances for $270-d$ lactation yields presented in Table 6 .

Correlations across breeds for the 3 Legendre polynomials are shown in Table 7 . Virtually no differences existed among permanent environmental effects for both breeds. This could indicate that breed-specific permanent environmental effects are not important, even if variance differences exist across breeds. Herdperiod regression effects differed strongly, with correlations between 0.755 and -0.040 . Because these effects translate into herd-specific lactation curves within breeds, these results could indicate not only that lactation curves among breeds are different, but also that breeds are managed differently, or at least that they react differently to a common management (Bryant et al., 2007b). Direct interpretation of these results on a herd level could also indicate the existence of breedspecific competition effects that vary through the different lactation stages. Correlations were very high for the constant genetic effect (0.926), but decreased to 0.604 for the quadratic genetic regressions. These results showed similar genetic rankings between the 2 breeds for the mean or overall milk yield. However, this does not mean that these ranking differences can be neglected completely, because top sires can rerank significantly, even with an overall correlation of 0.926. In addition, if other lactation shape parameters linked to persistency are considered, larger differences between $\mathrm{HF}$ and JE cattle seem to exist. This hypothesis is also supported by the values in Table 8 showing the genetic correlations between HF and JE cattle on a withinlactation basis. Some correlations, especially those linking different DIM, were as low as 0.600. Phenotypic correlations are not given across breeds because they would not make much sense.

Because we used an animal model, most of the information on genetic correlations might come from the difference between dam-daughter regressions when daughters are purebred compared with crossbred. They also reflect expected ranking differences in purebred offspring compared with crossbred offspring of a purebred sire.

Heritability estimates as a function of DIM, as illustrated in Figure 3, were low at the beginning and the end of lactation, whereas they were greater toward midlactation for JE purebreds and crossbreds. The HF purebred animals had a lower heritability than the JE animals during lactation. Daily estimates of genetic and phenotypic correlations between different stages of lactation and daily estimates of heritabilities are presented in Table 8. Results were similar to those from

Table 8. Heritabilities (diagonal), genetic correlations (above diagonal), and phenotypic correlations (below diagonal) for daily milk yields among first lactation estimated from multibreed models for Holstein-Friesian and Jersey animals, genetic correlations among Holstein-Friesian and Jersey animals

\begin{tabular}{|c|c|c|c|c|c|c|c|c|c|c|}
\hline DIM & \multicolumn{5}{|c|}{ DIM } & \multicolumn{5}{|c|}{ DIM } \\
\hline 5 & 0.155 & 0.916 & 0.729 & 0.604 & 0.540 & 0.852 & 0.822 & 0.771 & 0.722 & 0.600 \\
\hline 60 & 0.829 & 0.189 & 0.941 & 0.855 & 0.599 & 0.893 & 0.916 & 0.907 & 0.883 & 0.745 \\
\hline 120 & 0.609 & 0.755 & 0.233 & 0.972 & 0.632 & 0.826 & 0.885 & 0.910 & 0.914 & 0.805 \\
\hline 180 & 0.420 & 0.611 & 0.711 & 0.253 & 0.732 & 0.773 & 0.833 & 0.868 & 0.894 & 0.853 \\
\hline \multicolumn{6}{|l|}{5} & 0.218 & 0.981 & 0.943 & 0.918 & 0.845 \\
\hline \multicolumn{6}{|l|}{60} & 0.719 & 0.297 & 0.989 & 0.971 & 0.855 \\
\hline \multicolumn{6}{|l|}{120} & 0.537 & 0.625 & 0.331 & 0.993 & 0.865 \\
\hline \multicolumn{6}{|l|}{180} & 0.391 & 0.515 & 0.575 & 0.314 & 0.907 \\
\hline \multicolumn{6}{|l|}{270} & 0.347 & 0.384 & 0.397 & 0.413 & 0.281 \\
\hline
\end{tabular}


the single-breed analysis, with correlations becoming weaker as the interval between tests increased. Genetic correlations were again greater for JE than HF animals. However, this was not true for phenotypic correlations, for which values for JE were less.

\section{CONCLUSIONS}

Recently, an advanced test-day model that is adapted for its special breed structure was introduced in New Zealand. The present study investigated potential further advances for the future; (co)variance components and genetic parameters within and across breeds were estimated for HF and JE animals. Parameter estimates differed between single-breed and multibreed analyses. However, this could also have been due to differences between the purebred and nonpurebred herds used for these analysis or could have been artifacts resulting from the choice of the models. This indicates limitations in the design of this study, because it was assumed a priori that purebred and nonpurebred herds were more similar, and the model was designed having this in mind. Future studies should consider our findings. The genetic correlations across breeds, computed from the multibreed model, showed additive genetic differences, especially in linear and quadratic Legendre polynomials, which are linked to persistency. The results of this study showed that breed-dependent additive breeding values could be estimated by the proposed multibreed model and could therefore provide a theoretically better tool to evaluate a crossbred dairy cattle population, as found in New Zealand. However, the situation presented here was simplified because only 2 breeds were analyzed together. A routine model might require 10 or more different breed effects. Despite this, if in the future available computing resources increase and also if detecting genetic differences in lactation shape parameters becomes even more of an issue, models similar to the one presented in this study would be possible and worth considering. According to our findings, such a model could use a single permanent environmental effect. However, it would need distinct herd-period effects because results indicated the existence of breed-specific competition effects that varied through the different lactation stages. Scaling of variances would always be needed because we showed that rather large variance differences existed. Even intrabreed heritability differences may exist according to the environment (purebreed vs. multibreed herds). Therefore, future studies and a routine evaluation would still require the development of an improved methodology, and the model presented here is only a first step. Improved methodology would also address heterosis more correctly by estimating general, but potentially also specific, heterosis. Such a model would also be computationally very challenging because of the simultaneous presence of a larger number of breeds than the 2 breeds used in this study.

\section{ACKNOWLEDGMENTS}

Nicolas Gengler, research associate at the National Fund for Scientific Research (Brussels, Belgium), acknowledges its support. Additional support was provided through grants F.4552.5 and 2.4507.02F (2) of the National Fund for Scientific Research. Manuscript review and useful comments by P. M. VanRaden (Animal Improvement Programs Laboratory, ARS, USDA, Beltsville, MD) and 2 anonymous reviewers are acknowledged.

\section{REFERENCES}

Ahlborn, G., and L. Dempfle. 1992. Genetic parameters for milk production and body size in New Zealand Holstein-Friesian and Jersey. Livest. Prod. Sci. 31:205-219.

Bryant, J. R., N. López-Villalobos, J. E. Pryce, C. W. Holmes, D. L. Johnson, and D. J. Garrick. 2007a. Environmental sensitivity in New Zealand dairy cattle. J. Dairy Sci. 90:1538-1547.

Bryant, J. R., N. López-Villalobos, J. E. Pryce, C. W. Holmes, D. L. Johnson, and D. J. Garrick. 2007b. Effect of environment on the expression of breed and heterosis effects for production traits. J. Dairy Sci. 90:1548-1553.

Garrick, D. J., B. L. Harris, and D. L. Johnson. 1997. The across-breed evaluation of dairy cattle in New Zealand. Proc. Assoc. Advmt. Anim. Breed Genet. 12:611-615.

Harris, B. L. 1994. Animal model for New Zealand dairy cattle evaluation. Proc. 1994 Interbull Mtg. 10:1-13.

Harris, B. L. 1995. Animal evaluation methods for New Zealand dairy cattle. Pages 1-28 in Livest. Improvement Corp. Tech. Rep. Livest. Improve. Corp., Hamilton, New Zealand.

Harris, B. L., and E. S. Kolver. 2001. Review of Holsteinization on intensive pastoral dairy farming in New Zealand. J. Dairy Sci. 84(E Suppl.):E56-E61.

Harris, B. L., A. M. Winkelman, D. L. Johnson, and W. A. Montgomerie. 2006. Development of a national production testday for New Zealand. Interbull Bull. 35:27-30.

Interbull. 2007. Description of National Genetic Evaluation Systems for dairy cattle as applied in different Interbull member countries. http://www-interbull.slu.se/national_ges_info2/framesida-ges. htm. Accessed Oct. 19, 2007.

Jensen, J., E. A. Mäntysaari, P. Madsen, and R. Thompson. 1997. Residual maximum likelihood estimation of (co)variance components in multivariate mixed linear models using average information. J. Ind. Soc. Agric. Stat. 49:215-236.

Johnson, D. L. 1996. Estimation of lactation yield from repeated measures of test day yields. Proc. N. Z. Soc. Anim. Prod. 56:1618.

Legates, J. E. 1962. Heritability of fat yields in herds with different production levels. J. Dairy Sci. 45:990-993.

Lofgren, D. L., W. E. Vinson, R. E. Pearson, and R. L. Powell. 1985. Heritability of milk yield at different herd means and variance for production. J. Dairy Sci. 68:2737-2739.

Lopez-Villalobos, N., and D. J. Garrick. 1996. Profitability of rotational crossbreeding programmes in commercial dairy herds. Proc. N.Z. Soc. Anim. Prod. 56:216-220.

Lopez-Villalobos, N., and D. J. Garrick. 1997. Crossbreeding for increased profitability. Proc. Massey Univ. Dairy Farmers Conf., New Zealand 49:164-172.

Lopez-Villalobos, N., and D. J. Garrick. 2002. Economic heterosis and breed complementarity for dairy cattle in New Zealand. Page 228 
in Proc. 7th World Congr. Genet. Appl. Livest. Prod., Montpellier, France.

Lopez-Villalobos, N., D. J. Garrick, and C. W. Holmes. 2002. Genetic opportunities to improve milk value in New Zealand. Proc. N. Z. Soc. Anim. Prod. 62:90-94.

Lutaaya, E., I. Misztal, J. W. Mabry, T. Short, H. H. Timm, and R. Holzbauer. 2001. Genetic parameter estimates from joint evaluation of purebreds and crossbreds in swine using the crossbred model. J. Anim. Sci. 79:3002-3007.

Meyer, K. 1997. An 'average information' restricted maximum likelihood algorithm for estimating reduced rank genetic covariance matrices or covariance functions for animal models with equal design matrices. Genet. Sel. Evol. 29:97-116.

Misztal, I. 2002. REMLF90 manual. Dept. Anim. Dairy Sci., Univ. Georgia, Athens. http://nce.ads.uga.edu/ ignacy/ Accessed Oct. 19, 2007.

Misztal, I., T. Strabel, J. Jamrozik, E. A. Mäntysaari, and T. H. E. Meuwissen. 2000. Strategies for estimating the parameters needed for different test-day models. J. Dairy Sci. 83:1125-1134.

Montgomerie, W. A. 2002. Experiences with dairy cattle crossbreeding in New Zealand. Pages 1-12 in 53rd Annu. Mtg. Eur. Assoc.
Anim. Prod., Cairo, Egypt. http://www.aeu.org.nz/news/EAAP_ Xbreed_Sept2002.PDF Accessed Oct. 19, 2007.

Newman, S., A. Reverter, and D. J. Johnston. 2002. Purebred-crossbred performance and genetic evaluation of postweaning growth and carcass traits in Bos indicus $\times$ Bos taurus crosses in Australia. J. Anim. Sci. 80:1801-1808.

Roso, V. M., F. S. Schenkel, S. P. Miller, and J. W. Wilton. 2005. Additive, dominance, and epistatic loss effects on preweaning weight gain of crossbred beef cattle from different Bos taurus breeds. J. Anim. Sci. 83:1780-1787.

Touchberry, R. W. 1992. Crossbreeding effects in dairy cattle: The Illinois experiment, 1949 to 1969. J. Dairy Sci. 75:640-667.

VanRaden, P. M., and A. H. Sanders. 2001. Economic merit of crossbred and purebred US dairy cattle. J. Dairy Sci. 86:1036-1044.

Wei, M., and J. H. J. van der Werf. 1995. Genetic correlation and heritabilities for purebred and crossbred performance in poultry egg production traits. J. Anim. Sci. 73:2220-2226.

Zumbach, B., I. Misztal, S. Tsuruta, J. Holl, W. Herring, and T. Long. 2007. Genetic correlations between two strains of Durocs and crossbreds from differing production environments for slaughter traits. J. Anim. Sci. 85:901-908. 